\title{
Deriva simulada de glyphosate em plantas jovens de jenipapo (Genipa americana L.) ${ }^{1}$
}

\section{Simulated drift of glyphosate in jenipapo (Genipa americana L.) young plants}

\author{
Graziele Araujo Gusmão ${ }^{2}$, Rubens Marques Rondon Neto ${ }^{3}$, Oscar Mitsuo Yamashita ${ }^{4}$
}

\begin{abstract}
Resumo - O presente trabalho teve como objetivo avaliar os efeitos de subdoses de glyphosate em plantas jovens de jenipapo (Genipa americana L.). Um ano após o plantio das mudas, foram testadas três subdoses de glyphosate, sendo: T1 - 86,4, T2 - 172,8 e T3 - 345,6 g i.a. ha ${ }^{-1}$ e T4 Testemunha (sem aplicação). Aos 7, 14, 21, 28 e 120 dias após a aplicação (DAA) do herbicida foram dadas notas para fitointoxicação visual, sendo que na primeira e última avaliação realizaram-se medições da altura e diâmetro do colo das plantas. Após 120 DAA observou-se que a espécie $G$. americana foi sensível a aplicação do herbicida glyphosate, afetando de forma significativa o crescimento em altura e não o diâmetro da planta. Dosagens de glyphosate superiores a 86,4 g i.a. ha ${ }^{-1}$ causaram apenas danos, no entanto, com 345,6 g i.a. ha ${ }^{-1}$ ocorreu morte das plantas.
\end{abstract}

Palavras-chave: Herbicida, fitotoxidade, área degradada.

\begin{abstract}
This study aimed to evaluate the effects of glyphosate sub doses in genipap (Genipa americana L.) young plants. One year after seedlings planting, three glyphosate sub doses were tested, being: T1 - 86.4, T2 - 172.8 and T3 - 345.6 g i.a. ha ${ }^{-1}$ and T4 - Check (without application). At 7, 14, 21, 28 and 120 days after herbicide application (DAA) scores were provided for visual phytotoxicity, and in the first and in the last evaluation, measurements of plant height and plant diameter were conducted. After 120 DAA it was observed that G. americana specie was sensitive to glyphosate herbicide application, affecting significantly height growth, but not plant diameter. Glyphosate doses superior than 86.4 g a.e. ha $^{-1}$ caused only damages, however, with $345.6 \mathrm{~g}$ a.e. $\mathrm{ha}^{-1}$ occurred plant death.
\end{abstract}

Key words: Herbicide, phytotoxicity, degraded land.

\footnotetext{
* Autor para correspondência

${ }^{1}$ Recebido para publicação em 14/02/2011 e aceito25/03/2011.

2 Acadêmica do curso de Engenharia Florestal da UNEMAT - Universidade do Estado de Mato Grosso, Campus de Alta Floresta/MT. E-mail: graziele_gusmao@hotmail.com

${ }^{3}$ Professor Adjunto do Depto. de Engenharia Florestal da UNEMAT - Universidade do Estado de Mato Grosso, Campus de Alta Floresta/MT. Av. Rogério Silva, s/n - Jd. Flamboyant, CEP: 78580-000, Alta Floresta/MT. E-mail: rubensrondon@yahoo.com.br;

${ }^{4}$ Professor Adjunto do Depto. de Agronomia da UNEMAT - Universidade do Estado de Mato Grosso, Campus de Alta Floresta/MT. E-mail: yama@ unemat.br
}

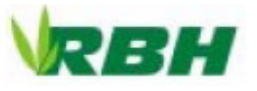


Gusmão et al.

\section{Introdução}

A manutenção das áreas degradadas em processo de recuperação deve ser realizada até o recobrimento do solo pela sombra da copa das árvores, eliminando-se os indivíduos competidores da área. A falta de controle das plantas daninhas tem sido a principal causa do insucesso da prática de recuperar as áreas degradadas (Attanasio, 2008). Em geral, nessas áreas são necessárias de diversas ações de controle de plantas competidoras, basicamente concentradas no período chuvoso, realizadas por meio de métodos de controle manual, mecânico ou químico, integrados ou não.

Dentre os problemas encontrados para a recuperação dessas áreas, encontra-se o controle de plantas daninhas no início do processo de regeneração natural ou artificial, pois ocorre a competição entre as espécies de recuperação e as plantas daninhas. Uma das alternativas de controle utilizadas é a aplicação de herbicidas não seletivos que, quando em contato com a planta, podem provocar danos como o atraso do seu desenvolvimento e até mesmo a sua morte. Considerando que o controle de plantas daninhas é uma das atividades de maior custeio para a recuperação, torna-se necessário a implantação de métodos eficientes, que apresentem baixo custo de utilização.

Dessa forma, uma das alternativas é o uso de glyphosate, que apresenta características como grande espectro de ação tanto em espécie mono quanto dicotiledôneas. É um produto não seletivo e sistêmico aplicado geralmente em jato dirigido ou em faixas de plantio, com intuito de evitar também a deriva que pode atingir plantas jovens, ocasionando injúrias não desejadas. Portanto, torna-se necessário a geração de informações sobre a fitotoxidade desse herbicida sobre espécies florestais utilizadas no processo de recuperação de áreas degradadas.
Dentre as inúmeras espécies florestais nativas com potencialidade de utilização nos programas de recuperação das áreas degradadas no Brasil, tem-se o jenipapo (Genipa americana L.). Esta espécie arbórea tem característica de planta heliófita, semidecídua, seletiva higrófita, com ocorrência em várias formações florestais situadas em várzeas úmidas e brejosas (Lorenzi, 1992). Por sua tolerância ao excesso de umidade do solo e o fato de seus frutos serem muito atrativos à fauna silvestre, têm sido utilizada frequentemente nos projetos de reabilitação de áreas de preservação permanente e reserva legal degradadas.

Desse modo, o presente trabalho tem como objetivo avaliar os efeitos fitotóxicos de subdoses crescentes de glyphosate em plantas jovens de jenipapo (Genipa americana L.), a fim de subsidiar o processo de recuperação das áreas degradadas na região norte do Estado de Mato Grosso.

\section{Material e Métodos}

O experimento foi instalado na área experimental do Campus Universitário de Alta Floresta, pertencente à UNEMAT Universidade do Estado de Mato Grosso, localizada no extremo norte do Estado de Mato Grosso. O ponto central dessa área apresenta as coordenadas geográficas $10^{\circ} 06^{\prime} 53^{\prime \prime} \mathrm{S}$ e $56^{\circ} 12^{\prime} 02^{\prime \prime} \mathrm{W}$ a $284 \mathrm{~m}$ de altitude. $\mathrm{O}$ experimento foi conduzido entre o período de maio de 2009 e outubro de 2010.

Segundo a classificação de Köppen, a região apresenta clima tipo Awi, sendo tropical chuvoso com estação seca nítida de dois meses. A temperatura anual varia entre 20 e $38{ }^{\circ} \mathrm{C}$, tendo média de $26^{\circ} \mathrm{C}$. A precipitação pluviométrica é elevada (2.500 a $2.750 \mathrm{~mm})$ com intensidade máxima entre janeiro e março (Ferreira, 2001). O solo da área experimental é classificado como Latossolo Vermelho 
Gusmão et al.

amarelo-distrófico (Moreira e Vasconcelos, 2007).

A vegetação presente na área experimental era composta por capimbraquiarão (Brachiaria brizantha), sendo eliminado durante o preparo do solo, através de quatro operações de gradagens, na profundidade de aproximadamente $20 \mathrm{~cm}$. As mudas de Genipa americana L. utilizadas no plantio foram produzidas em tubetes de 50 $\mathrm{cm}^{3}$, sendo plantadas em campo quando apresentavam em altura média de $20 \mathrm{~cm}$, no mês de maio de 2011.

O plantio foi realizado em maio/2009, com espaçamento $1 \times 1 \mathrm{~m}$, em covas de $20 \mathrm{x}$ $20 \times 20 \mathrm{~cm}$ abertas com enxadão. No momento do plantio foram aplicados 0,3 litros de solução de hidrogel por cova, preparado na proporção de 3,0 $\mathrm{g} \mathrm{L}^{-1}$ de água. Este produto apresenta a característica de reter por mais tempo a água, reduzindo a frequência das irrigações. Durante o período de seca da região (maio a setembro), as mudas foram irrigadas quinzenalmente com 2,0 $\mathrm{L}$ de água. O controle das plantas daninhas foi realizado manualmente com o auxílio de enxada, capinando-se o entorno das plantas, na forma de coroamento.
O experimento foi instalado após um ano do plantio das mudas, utilizando-se delineamento de blocos ao acaso com quatro repetições. Cada unidade experimental foi composta por quatro plantas. Com a idade de um ano as mudas foram submetidas a subdoses de glyphosate, as quais constituíram os tratamentos testados, sendo: $\mathrm{T} 1$ - 86,4, T2 172,8 e T3 - 345,6 g i.a. ha ${ }^{-1}$, na dosagem de $3,0 \mathrm{~L} \mathrm{ha}^{-1}$ do produto comercial, e $\mathrm{T} 4$ Testemunha (sem aplicação). O herbicida utilizado foi o Gliz $480 \mathrm{SL}^{\circledR}$, com composição de glyphosate sob forma sal de isopropilamina (480 $\mathrm{g} \mathrm{L}^{-1}$ do equivalente ácido).

As aplicações das subdoses do herbicida foram realizadas utilizando pulverizador costal com pressão constante mantida por $\mathrm{CO}_{2}$ comprimido, munido de barra contendo uma ponta de pulverização de jato plano tipo XR 11002. A pressão de serviço utilizada foi de $2 \mathrm{kgf} \mathrm{cm}^{-2}$, proporcionando um volume de calda de $200 \mathrm{~L}$ ha $^{-1}$. A aplicação do herbicida foi realizada no período matutino, entre 8:00 e 9:00 horas, quando a temperatura média do ambiente era de $28{ }^{\circ} \mathrm{C}$, umidade relativa do ar em torno de $80 \%$ e com ausência de ventos.

Tabela 1. Escala de notas para avaliação visual do nível de fitotoxicidade de plantas de jenipapo (Genipa americana L.) submetidas à subdoses de glyphosate $\left(0,86,4,172,8\right.$ e 345,6 g i.a. ha $\left.{ }^{-1}\right)$.

\begin{tabular}{cl}
\hline Nota & \multicolumn{1}{c}{ Características } \\
\hline 0 & $\begin{array}{l}\text { Sem injúrias. Sem efeito sobre a cultura } \\
\text { Injúrias leves ou redução de crescimento com rápida recuperação. Efeitos } \\
\text { insuficientes para promover redução de produtividade. }\end{array}$ \\
& $\begin{array}{l}\text { Injúrias moderadas ou reduções de crescimento com lenta recuperação ou } \\
\text { definitivas. Efeitos intensos o suficiente para promover pequenas reduções de } \\
\text { produtividade. } \\
\text { Injúrias severas ou reduções de crescimento não recuperáveis ou reduções de } \\
\text { estande. Efeitos intensos o suficiente para promover drástica redução de } \\
\text { produtividade. } \\
\text { Destruição completa da cultura ou somente algumas plantas vivas. }\end{array}$ \\
\hline
\end{tabular}

Fonte: Sociedade Brasileira da Ciência das Plantas Daninhas (1995). 
Gusmão et al.

Após a aplicação do herbicida foram realizadas avaliações aos 7, 14, 21, 28 e 120 dias (DAA), sendo avaliadas as seguintes características: notas de fitotoxicidade visual (Tabela 1), altura das plantas e diâmetro do colo. Os dois últimos dados foram transformados em $\sqrt{x}+0,5$, e posteriormente submetidos à análise de variância, sendo as médias comparadas entre si pelo teste de Tukey, ao nível de 5\% de probabilidade.

\section{Resultados e discussão}

Em relação à avaliação do nível de fitointoxicação das subdoses de glyphosate simulando derivas em Genipa americana, foi constatado aos 7 DAA que $86,4 \mathrm{~g}$ i.a. ha $^{-1}$ apresentou $62,5 \%$ dos indivíduos com nível significativo de injúria (nota 1), e 12,5\% com nenhuma forma de injúria (nota 0), e o mesmo valor para injúrias moderadas e redução no crescimento (nota 2) e morte da planta (nota 4) (Figura 1). Após 14, 21 e 28 DAA observou-se a predominância do maior nível de injúria (nota 1), entretanto, após 120 DAA 62,5\% dos indivíduos recuperaram-se dos sintomas de fitotoxicação, voltando a não apresentar nenhum tipo de sintoma definido. Resultados semelhantes foram observados por Yamashita et al. (2009) ao utilizarem baixas concentrações do herbicida glyphosate em plantas de Schizolobium amazonicum e Ceiba petandra.

$\mathrm{Na}$ avaliação realizada aos 7 DAA, 172,8 g i.a. ha $^{-1}$ apresentou o mesmo resultado que T1. Contudo, aos 14 DAA, 62,5\% dos indivíduos apresentaram injúrias moderadas e redução no crescimento (nota 2). Aos 21 DAA, 37,5\% tiveram evolução dos sintomas, caracterizados por injúrias severas com a presença de necroses nas folhas e redução no crescimento não recuperáveis (nota 3), mantendo-se aos 28 DAA. Em avaliações realizadas aos 120 DAA, $75 \%$ dos indivíduos conseguiram se recuperar e não apresentavam nenhuma injúria.

Diferentemente dos tratamentos anteriores, 345,6 g i.a. ha ${ }^{-1}$ apresentou $75 \%$ de indivíduos com nível significativo de injúria (nota 1) aos 7 DAA. Aos 14 DAA, 37,5\% dos indivíduos estavam com injúrias moderadas e redução no crescimento (nota 2) e $50 \%$ com injúrias severas e redução no crescimento não recuperáveis (nota 3). Aos 120 DAA, houve uma recuperação significativa de $62,5 \%$ das plantas, apresentando apenas um nível significativo de injúrias (nota 1), indicando recuperação das plantas. Em contrapartida, houve redução no estande, indicando que a espécie apresentou sensibilidade ao referido tratamento. Para Magalhães et al. (2001), a deriva de glyphosate em plantas de milho proporcionou elevados níveis de injúrias. Além disso, os autores relatam que estes efeitos são diretamente proporcionais ao aumento da dose do herbicida.

Aos 120 DAA observou-se que as plantas jovens de Genipa americana demonstraram elevada sensibilidade às aplicações de todas as subdoses de glyphosate testadas. Resultados semelhantes foram encontrados por Tuffi Santos et al. (2005), trabalhando com simulação de deriva em eucalipto, observando que o surgimento dos sintomas está relacionado com a quantidade de produto em contato com as plantas e que estes eram observados já a partir de 5 DAA. Porém, Christoffoletti et al. (1998) ao aplicar glyphosate para o controle de plantas daninhas em Pinus taeda, não observaram nenhum sintoma aparente de injúria nas plantas, até mesmo na primeira observação aos 33 DAA. 
Gusmão et al.

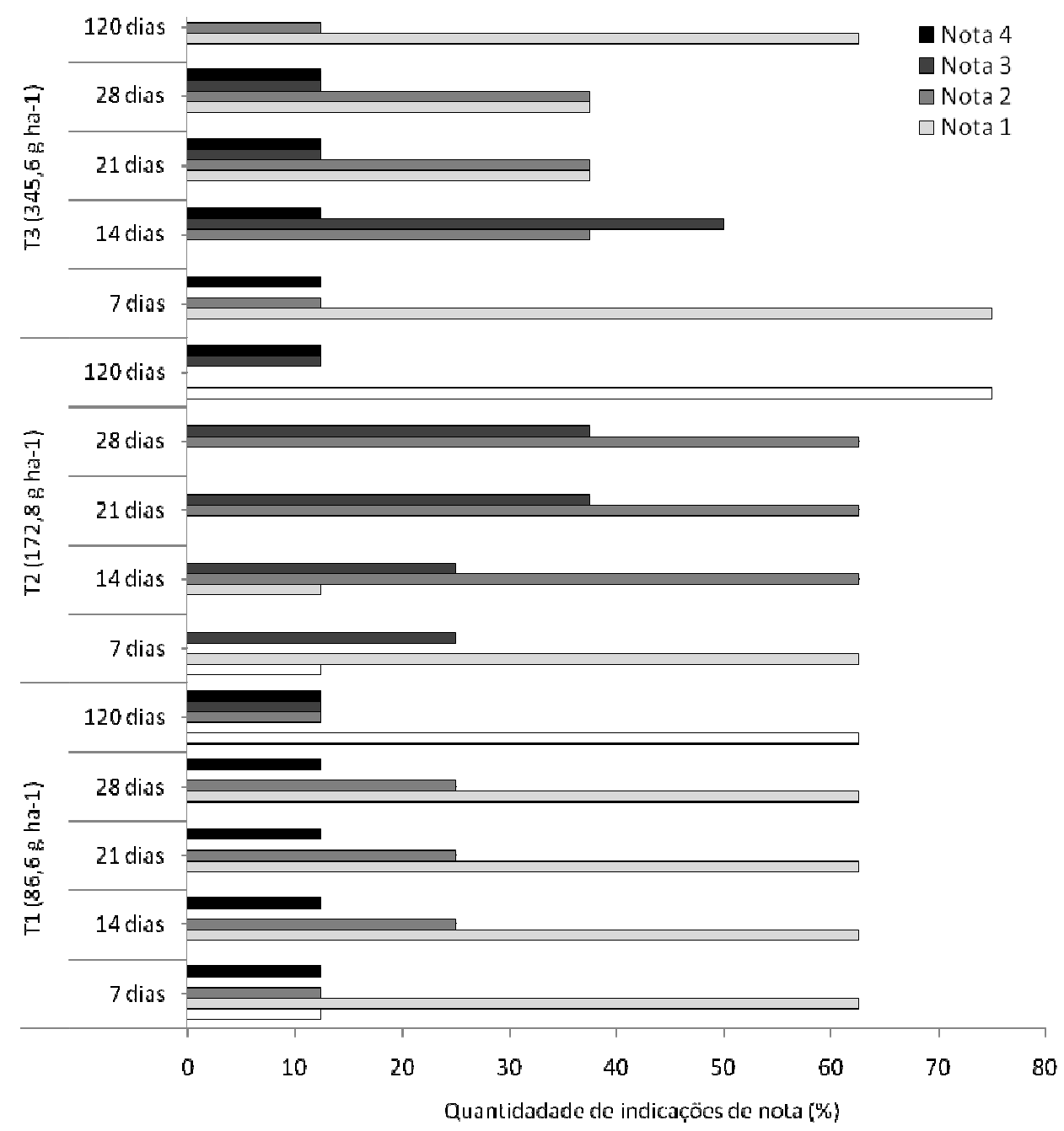

Figura 1. Percentual de indicações de notas do nível de fitotoxidade existente em plantas de jenipapo (Genipa americana) aos 7, 14, 21, 28 e 120 DAA de subdoses de glyphosate.

As plantas de Genipa americana estatísticas para o incremento em altura (Figura apresentaram elevados sintomas de injúrias 2A). Nas subdoses de 86,4 g i.a. ha ${ }^{-1}$ (T2) e como cloroses e necroses, em função da deriva $172,8 \mathrm{~g}^{\text {i.a. }} \mathrm{ha}^{-1}$ (T2) houve menor incremento do glyphosate, durante o período de avaliação, em altura durante esse período, não sendo sendo que todas as subdoses houve observada diferença significativa em relação à recuperação satisfatória dessas injúrias. No subdose $345,6 \mathrm{~g}$ i.a. ha ${ }^{-1}$ (T3), cujo tratamento entanto, houve significativa mortalidade de foi o que menos prejudicou o crescimento em plantas, caracterizando essa espécie como altura da planta, diferindo apenas do tratamento sensível ao glyphosate. Após 120 DAA, foi testemunha. Foloni et al. (2005) analisaram os constatado redução no crescimento em altura efeitos da aplicação de glyphosate em plantas das plantas jovens de Genipa americana, sendo de soja (Glycine max), verificaram que plantas que os tratamentos submetidos à aplicação do que receberam herbicidas apresentavam menor herbicida não demonstraram diferenças altura em relação as plantas testemunhas. 
Gusmão et al.

Yamashita et al. (2009) observaram que para Schizolobium amazonicum e Ceiba petandra houve uma forte redução na altura para a maior dose glyphosate aplicada.
(A)

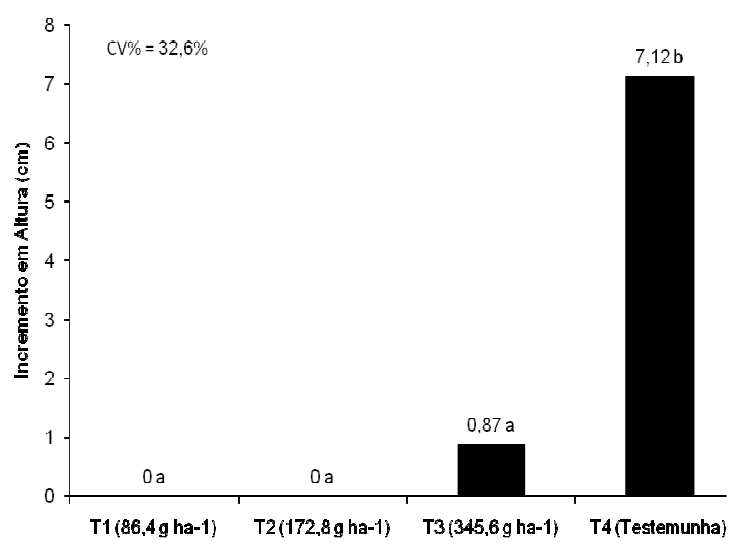

(B)

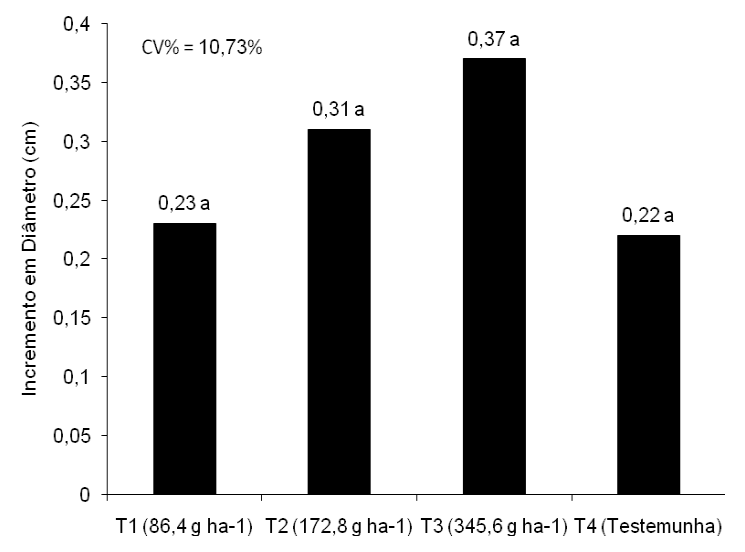

Figura 2. Incrementos em altura total (A) e diâmetro (B) das plantas de jenipapo (Genipa americana) 120 DAA de subdoses de glyphosate. Médias seguidas da mesma letra na coluna não diferem entre si pelo teste de Tukey, ao nível de 5\% de probabilidade.

As plantas jovens de Genipa americana não apresentaram crescimento em diâmetro do caule influenciado pela aplicação das subdoses de glyphosate, sendo que os tratamentos com glyphosate não diferiram significativamente da testemunha (T4) (Figura 2B). Houve um aumento proporcional do incremento diamétrico com o aumento da dose de glyphosate. Portanto, dentre as subdoses utilizadas, 86,4 g i.a. ha ${ }^{-1}$ de glyphosate foi o que mais interferiu em relação ao crescimento em diâmetro dos indivíduos.

As subdoses de glyphosate foram prejudiciais aos indivíduos de Genipa americana em relação ao crescimento em diâmetro, entretanto, não apresentaram diferenças estatísticas. Yamashita et al. (2006) também observaram que para aplicação de 90 , 180, 360 e 720 g i.a. ha ${ }^{-1}$ de glyphosate, não houve diferenças significativas no diâmetro do caule de mudas de varjão (Parkia multijuga). A mesma situação também foi observada por França et al. (2010), ao estudar o efeito do glyphosate sobre crescimento e teores de nutrientes em cultivares de café arábica, onde relataram que o diâmetro do caule não foi afetado pelo herbicida.

Pelo motivo do glyphosate não ser seletivo para as espécies florestais, entre elas Genipa americana, torna-se necessária a aplicação dirigida da calda nas proximidades da plantas jovens. A deriva desse herbicida pode provocar danos às plantas, causando atraso no desenvolvimento ou até mesmo a morte de alguns indivíduos. Tal fato poderia ser limitante ao sucesso do reflorestamento com fins ambientais, principalmente quando se trata de recuperação de áreas degradadas.

\section{Conclusão}

A simulação de deriva de glyphosate em Genipa americana promoveu danos em aplicação de subdoses superiores a 86,4 g i.a. ha $^{-1}$, sendo para 345,6 g i.a. ha ${ }^{-1}$ ocorreu morte das plantas. 
Gusmão et al.

\section{Referências}

ATTANASIO, C.M. Manual técnico: restauração e monitoramento de mata ciliar e da reserva legal para certificação agrícola conservação da biodiversidade na cafeicultura. Piracicaba/SP: Imaflora, 2008. 60p.

CHRISTOFFOLETI, P.J. et al. Controle de plantas daninhas em Pinus taeda através do herbicida Imazapyr. Piracicaba/SP: IPEF, 1998. 11p. (Circular técnica, 187).

FERREIRA, J.C.V. Mato Grosso e seus municípios. Cuiabá/MT: Secretaria de Estado da Educação, 2001. 365p.

FRANÇA, A.C. et al. Crescimento de cultivares de café arábica submetidos a doses do glyphosate. Planta Daninha, v.28, n.3, p.599-607, 2010.

FOLONI, L.L. et al. Aplicação de glifosato em pós-emergência, em soja transgênica cultivada no cerrado. Revista Brasileira de Herbicidas, v.4, n.3, p.47-58, 2005.

LORENZI, H. Árvores brasileiras: manual de identificação e cultivo de plantas arbóreas nativas do Brasil. Nova Odessa/SP: Plantarum. 1992.

MAGALHÃES, P.C. et al. Efeito de doses reduzidas de glyphosate e paraquat simulando deriva na cultura do milho. Planta Daninha, v.19, n.2, p.247-253, 2001.

MOREIRA, M.L.C.; VASCONCELOS, T.N.N. Mato Grosso: solos e paisagens. Secretaria de planejamento e coordenação geral. SEPLAN/MT. Cuiabá/MT, 2007, 272p.

SOCIEDADE BRASILEIRA DA CIÊNCIA DAS PLANTAS DANINHAS. Procedimentos para instalação, avaliação e análise de experimentos com herbicidas. Londrina: SBCPD, 1995. 42p.

TUFFI SANTOS, L.D. et al. Crescimento e morfoanatomia foliar de eucalipto sob efeito de deriva do glyphosate. Planta Daninha, v.23, n.1, p.133-142, 2005.

YAMASHITA, O.M. et al. Influência do glyphosate e 2,4-D sobre o desenvolvimento inicial de espécies florestais. Scientia Forestalis, v.37, n.84, p.359-366, 2009.

YAMASHITA, O.M. et al. Resposta de varjão (Parkia multijuga) a subdoses de glyphosate. Planta Daninha, v.24, n.3, p.527-531, 2006. 